ELECTRONIC LETTER

\title{
Y-linked inheritance of non-syndromic hearing impairment in a large Chinese family
}

\author{
Q J Wang, C Y Lu, N Li, S Q Rao, Y B Shi, D Y Han, X Li, J Y Cao, L M Yu, Q Z Li, M X Guan, \\ W Y Yang, Y Shen
}

J Med Genet 2004;41:e80 (http://www.jmedgenet.com/cgi/content/full/41/6/e80). doi: 10.1136/jmg.2003.012799

$\mathrm{H}$ earing impairment is a common condition responsible for communication disorders affecting one in 1000 newborns. ${ }^{12}$ A national poll by the China Association of the Handicapped in 1987 showed that 20.57 million people in the country were affected by auditory or speech disorders, accounting for $34 \%$ of the 60 million disabled or $1.58 \%$ of the total Chinese population ( 1.3 billion) (www.cdpf.org.cn). Hearing impairment is caused by environmental and hereditary factors. Environmental factors include perinatal infection, acoustic or cerebral trauma affecting the cochlea, and ototoxic drugs such as aminoglycoside antibiotics. ${ }^{3}{ }^{4}$ Genetic factors contribute to $50 \%$ of deafness cases including syndromic (30\%) and non-syndromic (70\%) hearing impairment. ${ }^{15}$ Recent times have witnessed rapid progress in the field of genetic studies of hereditary hearing impairment, especially non-syndromic hearing impairment. Transmission of non-syndromic hearing impairment can be autosomal recessive $(77 \%)$, autosomal dominant $(22 \%)$, X-linked ( $1 \%)$, or matrilineal (mitochondrial inheritance, about $1 \%) .{ }^{4}$ More than 70 genetic loci have been characterised-that is, 37 for autosomal dominant, 34 for autosomal recessive, and 4 for $\mathrm{X}$-linked forms of non-syndromic hearing impairment. A total of 36 genes (34 nuclear and two mitochondrial) have so far been identified. ${ }^{67}$ To date, there has not been any report on Y-linked inheritance of hearing impairment.

Recently, the Institute of Otolaryngology of the Chinese People's Liberation Army (PLA) General Hospital has initiated a national network for collecting pedigrees of hereditary hearing loss. By collaborating with organisations for disabled people throughout China, many pedigrees with hereditary hearing loss have been identified and studied for deafness related genes. ${ }^{89}$ This paper describes a highly unusual finding of an extended seven-generation Chinese pedigree with hearing impairment clearly vertically inherited through males. The inheritance characteristics in this family cannot be explained by the four transmission mechanisms mentioned above. A Y-linked inheritance pattern is thus proposed based upon the data of pedigree analysis, segregation analysis and linkage analysis with 382 autosomal microsatellite markers at the spacing of an average of $8.6 \mathrm{cM}$ throughout the genome.

\section{SUBJECTS AND METHODS}

Pedigree recruitment and phenotypic evaluation

Details of a seven generation Chinese family (fig l) were ascertained from the Department of Otolaryngology, Head, and Neck Surgery, at the Institute of Otolaryngology, PLA General Hospital. Informed consent, blood samples, and clinical evaluations were obtained from all participants of this family according to the protocols approved by the PLA General Hospital Institution Review Board. Members of this pedigree were extensively interviewed by experienced ear, nose, and throat doctors and physicians to identify either personal or family medical evidence of hearing impairment,

\section{Key points}

- We report here the clinical and genetic characterisation of a very large Chinese family $(129$ members in seven generations) with non-syndromic hearing impairment.

- The striking feature in this family is the extremely high penetrance $(91 \%)$ in the patrilineal relatives, but almost no penetrance in the matrilineal relatives. Deafness was bilateral, symmetrical, sensorineural, postlingual, and progressive.

- Complex segregation analysis indicates that a putative major gene was segregating in the pedigree $(p=0.014)$, but it does not follow autosomal Mendelian inheritance $(p=0.001)$.

- Two point and multipoint model based linkage analysis showed that there is no genome wide significant lod score at 382 microsatellite markers covering 22 autosomal chromosomes to implicate an autosomal locus.

- Y-linked inheritance is thus proposed to be the genetic mode of transmission of the hearing impairment within this family.

tinnitus, vestibular symptoms, use of aminoglycosides, and other clinical abnormalities. The proband and his relations were then given physical examinations of the hair, skin, sclera, iris, mouth, maxilla, mandible, eyes, interocular distance, spine, and extremities. Otolaryngological examinations focused on the auricle, external auditory meatus, and tympanic membrane.

Audiometric evaluations of the proband and other members of this family were performed, including pure tone audiometry (Madsen 502, Denmark), EAR-3A insert earphones (USA), tympanometry and acoustic reflexes using a Madsen 901 (Denmark), and auditory brainstem responses using SmartEP (USA). The audiological data were evaluated based on the recommendations of the EU HEAR project, as described by Stephens. ${ }^{10}$ Sensorineural hearing impairment was defined as an air/bone gap $<15 \mathrm{~dB}$ hearing loss averaged over $0.5,1$, and $2 \mathrm{kHz}$. The severity of hearing impairment was applied to the better hearing ear, averaged over 0.5, 1, 2, and $4 \mathrm{kHz}$ and was categorised as follows: mild $=20-40 \mathrm{~dB}$ hearing loss; moderate $=41-70 \mathrm{~dB}$ hearing loss; severe $=71-$ $95 \mathrm{~dB}$ hearing loss; and profound $>95 \mathrm{~dB}$ hearing loss. Frequency ranges were defined: low frequencies $\leqslant 0.5 \mathrm{kHz}$; mid frequencies $>0.5 \mathrm{kHz} \leqslant 2 \mathrm{kHz}$; high frequencies

Abbreviation: df, degrees of freedom 
$>2 \mathrm{kHz} \leqslant 8 \mathrm{kHz}$; extended high frequencies $>8 \mathrm{kHz}$. In this family, individuals were considered as having inherited sensorineural hearing impairment if the hearing deficit occurred before the third decade. To investigate if chromosomal aberrations could be a putative genetic cause for the phenotypic manifestations, standard karyotype analysis was performed on some family members as well.

\section{Segregation analysis}

Before the model based genome wide linkage analysis of the large and extended pedigree with non-syndromic hereditary hearing loss, with a total of 129 members, segregation analysis was performed to investigate the presence of major type effects and segregation patterns within the pedigree using the newly developed S.A.G.E. program SEGREG for binary phenotypes. ${ }^{11}$ Three married-in members without offspring were excluded from the segregation analysis due to unrelatedness. This unique pedigree contains seven generations with 40 sibships (mean sibship size of 2.1) and is with about equal numbers of both sexes and 33 members affected with non-syndromic hereditary hearing loss. According to the classification of relative pairs in the pedigree, it contains 264 first degree relative pairs (parentoffspring and sibling pairs), 459 second degree relative pairs (grandparent-grandchild and avuncular pairs) and 360 third degree relative pairs (cousin pairs). Because of the characteristic of fairly uniformly early age at onset (7-27), we did not fit variable age at onset distribution for this analysis.

Regressive multivariate logistic models for binary traits were used to investigate the segregation pattern within the pedigree. $^{12}$ These assume, on the basis of the major phenotypical characteristics of any individual belonging to one or other of two nuclear families, that the two families are likely to be independent. ${ }^{11}$ In this model, the marginal probability (called susceptibility) that any pedigree member has a particular phenotype is the same for all members who have the same values of any covariates in the model and is given by the cumulative logistic function:

$$
\gamma=\frac{e^{\theta_{i} y_{i}}}{1+e^{\theta_{i}}}
$$

where $y_{i}$ is the trait value for the $i$ th individual and is 1 for an affected individual and 0 for an unaffected individual; and $\theta_{i}$ is the logit of the susceptibility for the $i$ th individual, which depends on the major type $(u=\mathrm{AA}$ or $\mathrm{AB}$ or $\mathrm{BB})$ and covariates $x_{i 1}, x_{i 1}, \ldots, x_{i p}$ :

$$
\theta_{u}(i)=\beta_{u}+\xi_{1} x_{i 1}+\ldots+\xi_{p} x_{i p}
$$

The nuclear familial residual association parameter $(\rho)$, which is analogous to the correlation parameter in regressive models for continuous traits, ${ }^{13}$ is a second order correlation and is incorporated into the models to account for residual polygenic and common environment effects. We assumed no spouse correlation and equal parent-offspring and sib-sib correlation throughout the analyses. Ascertainment bias was corrected by modelling the simplex sampling scheme from which the pedigree was recruited.

Four criteria proposed for inferring a major gene ${ }^{14}$ were used to test the specific hypothesis: a) rejection of the hypothesis of no major effects; $b$ ) rejection of the hypothesis of no transmission of major effects; $c$ ) failure to reject the hypothesis of Mendelian transmission; and $d$ ) rejection of the hypothesis of any particular Mendelian inheritance models (dominant, recessive, and general Mendelian models). Hypotheses were assessed by the likelihood ratio test, under the assumption that the negative of twice the difference in natural logarithms for hierarchical models follows a $\chi^{2}$ distribution. ${ }^{15}$

The S.A.G.E. program SEGREG estimates following parameters:

- $q_{\mathrm{A}}$, the frequency of the putative disease allele $(\mathrm{A})$;

- $\tau_{\mathrm{AA}}, \tau_{\mathrm{AB}}$, and $\tau_{\mathrm{BB}}$, the probability that an individual of type $\mathrm{AA}, \mathrm{AB}$, or $\mathrm{BB}$ transmits the $A$ allele to an offspring (for the Mendelian case, these correspond to 1.0, 0.5, and 0.0, respectively);

- $\operatorname{Susc}_{\mathrm{AA}}, \operatorname{Susc}_{\mathrm{AB}}$, and $\operatorname{Susc}_{\mathrm{BB}}$, the susceptibility on the logit scale that major type $\mathrm{AA}, \mathrm{AB}$, or $\mathrm{BB}$ confers a specific risk that an individual with that type develops non-syndromic hereditary hearing loss; and

- $\rho$, the first degree second moment familial correlation coefficient measuring residual multifactorial (polygenic and common environment) effects.

\section{Linkage analysis}

Genomic DNA was isolated from whole blood of 43 of 50 family members, who received clinical auditory evaluations. Three hundred and eighty two microsatellite markers spanning the 22 autosomes were obtained from PerkinElmer Applied Biosystems (ABI Prism Linkage Mapping Sets, version 2). These markers have an average population heterozygosity of $\approx 0.79$ and are spaced by an average of $8.6 \mathrm{cM}$ throughout the human genome. Multiplex PCR was

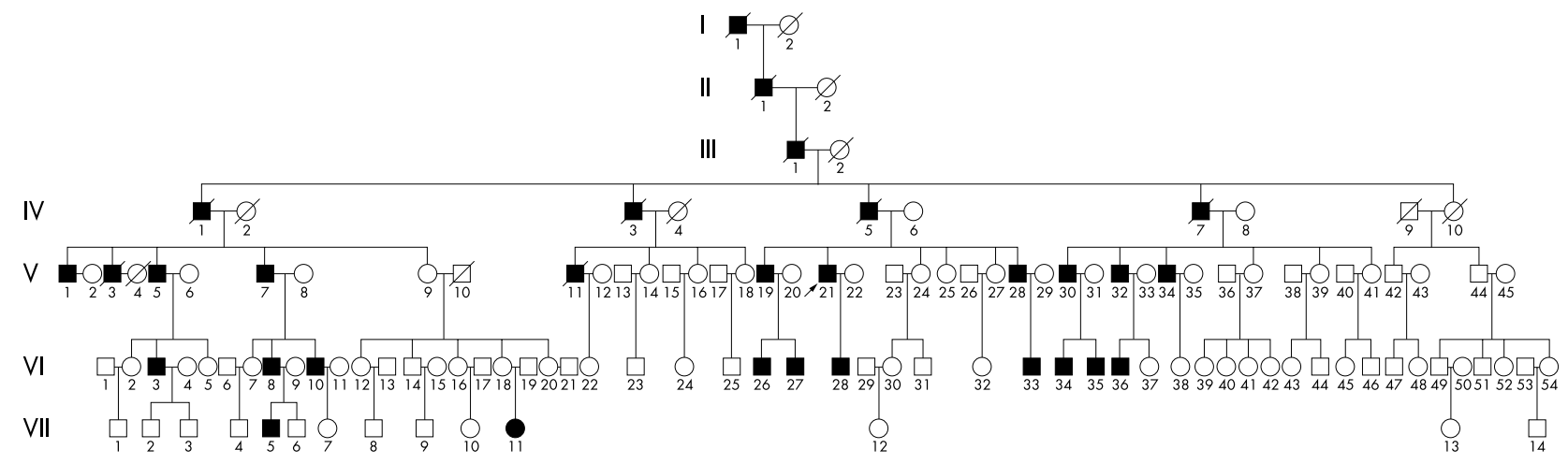

Figure 1 A Chinese pedigree with Y-linked inheritance of non-syndromic hearing impairment. Affected individuals are indicated by the filled symbols. Generations are indicated on the left by Roman numerals, and the numbers under the individuals represent identification numbers for each generation. The proband is identified by an arrow. 
performed with PE9600 thermocyclers (Applied Biosystems), producing a final volume of $5 \mu \mathrm{l}$ reaction mixture containing $30 \mathrm{ng}$ of genome DNA, $1 \times$ PCR buffer, $0.2 \mathrm{mM}$ of each dNTP, $3.0 \mathrm{mM} \mathrm{MgCl} 2,80 \mathrm{pmol}$ of each of the forward and reverse primers, and 0.2 units of Gold Ampli Taq Polymerase. Reactions were performed based on the instructions provided by the manufacturers and the products were loaded onto a $6 \%$ denaturing polyacrylamide gel ( $7 \mathrm{M}$ urea) and visualised on an ABI 377 sequencer. Alleles were analysed with Genescan analysis software (version 3.0) and Genotyper software (version 2.1).

Two point lod scores between the disease locus and markers were calculated by the MILNK program of the LINKAGE software package. ${ }^{16}$ The disease was hypothesised to be an autosomal dominant trait with a disease allele frequency of 0.0001 . The allele frequencies for each marker and for each sex were assumed to be equal. We assumed $90 \%$ penetrance for lod score calculation instead of $100 \%$ because of the possible misinterpretation of the phenotype in some cases. The values for the maximum lod score $\left(Z_{\max }\right)$ were calculated by the ILINK program of the LINKAGE package. Multipoint lod scores were calculated using GENEHUNTER software for efforts to fully utilise partial information along the nearby markers and to verify the putative linkage regions identified from the two point model based linkage analysis. ${ }^{17}$ In the multipoint analyses, we assumed a trait locus of dominant inheritance and $90 \%$ penetrance, the parametric settings for the maximum lod scores attainable for the two point linkage analysis.

\section{RESULTS}

\section{Clinical description}

The family originated from Jiangxi Province in southeastern China. Most of the family members have been living in the same region for over 200 years. As shown in fig 1, this family history is consistent with patrilineal inheritance. Very strikingly, none of the femal offspring of deaf fathers, except an affected female VII-11, who received gentamicin $(0.75 \mathrm{~g} /$ day for 3 days $)$ repeatedly for pneumonia at the age of 3 years, had a hearing impairment. On the contrary, 29 out
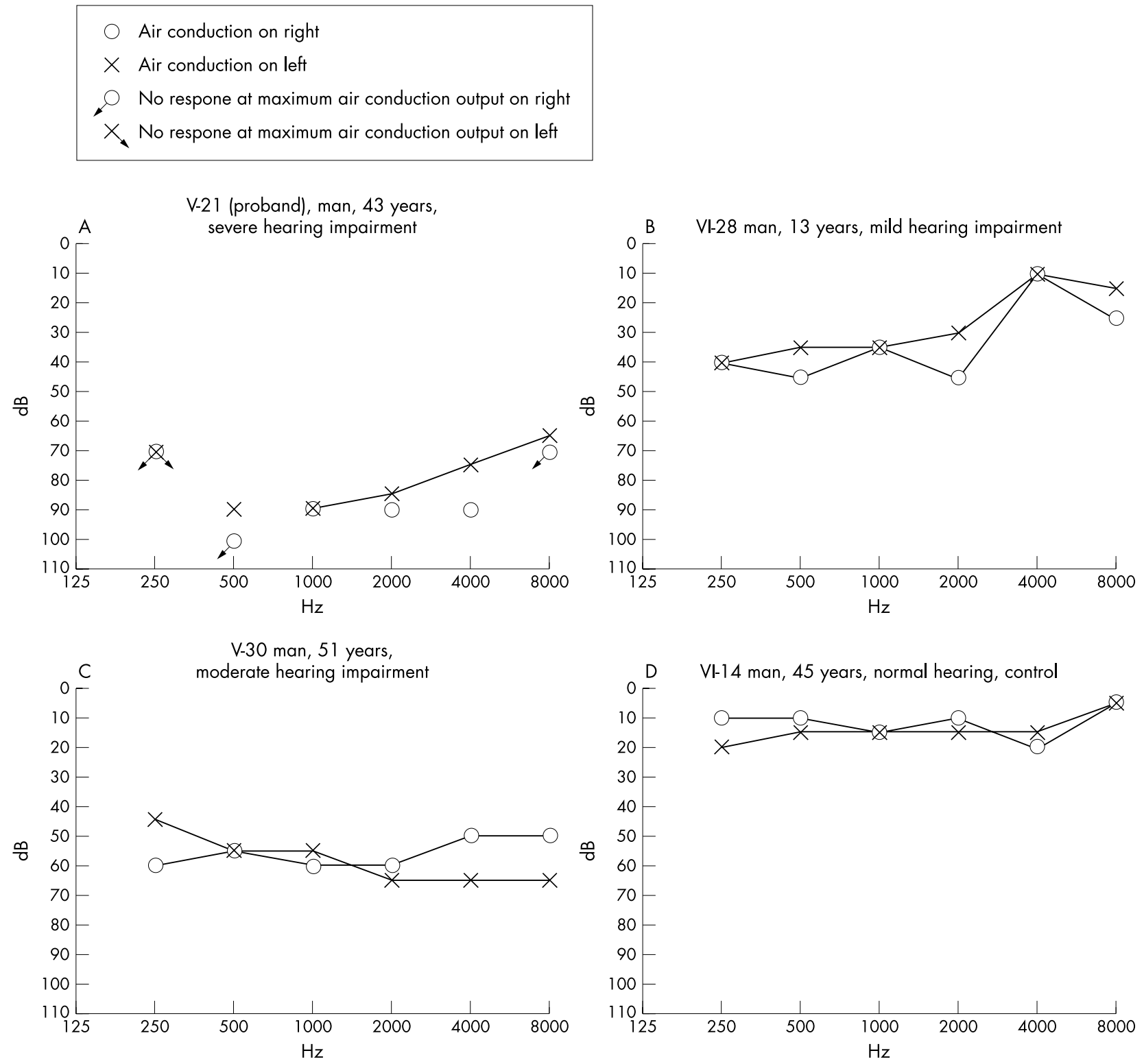

Figure 2 Audiograms of three affected individuals and one matrilineal male control. V-21 (proband) showed severe hearing impairment (A); VI-28 suffered mild hearing impairment (B); V-30 showed moderate hearing impairment (C); and VI-14, as a control, exhibited normal hearing (D). 
Table 1 Summary of clinical data for some patrilineal members in the Chinese pedigree

\begin{tabular}{|c|c|c|c|c|c|c|}
\hline Subject & Sex & Age of test (years) & Age of onset (years) & $\begin{array}{l}\text { Pure tone audiometry } \\
\text { (dB hearing loss), right }\end{array}$ & $\begin{array}{l}\text { Pure tone audiometry } \\
\text { (dB hearing loss), left }\end{array}$ & Hearing impairmen \\
\hline V-1 & Male & 71 & 7 & 85 & 80 & severe \\
\hline$V-5$ & Male & 55 & 22 & 75 & 67 & moderate \\
\hline$\vee-7$ & Male & 63 & 12 & 78 & 78 & severe \\
\hline V-19 & Male & 54 & 8 & 70 & 63 & moderate \\
\hline$V-21$ & Male & 45 & 27 & 90 & 85 & severe \\
\hline$V-30$ & Male & 51 & 20 & 56 & 60 & moderate \\
\hline$V-32$ & Male & 48 & 8 & 78 & 77 & severe \\
\hline V-34 & Male & 42 & 9 & 79 & 74 & severe \\
\hline $\mathrm{VI}-3$ & Male & 24 & 7 & 84 & 73 & severe \\
\hline VI-8 & Male & 32 & 7 & 76 & 75 & severe \\
\hline VI-10 & Male & 35 & 20 & 73 & 80 & severe \\
\hline VI-26 & Male & 23 & 18 & 76 & 78 & severe \\
\hline VI-27 & Male & 22 & 8 & 64 & 60 & moderate \\
\hline VI-28 & Male & 13 & 13 & 35 & 28 & mild \\
\hline VI-34 & Male & 26 & 8 & 58 & 64 & moderate \\
\hline VI-35 & Male & 22 & 18 & 65 & 60 & moderate \\
\hline $\mathrm{VI}-36$ & Male & 11 & 9 & 80 & 79 & severe \\
\hline VII-5 & Male & 9 & 7 & 83 & 75 & severe \\
\hline VII-2 & Male & $<1$ & - & not applicable & not applicable & normal \\
\hline VII-3 & Male & 2 & - & not applicable & not applicable & normal \\
\hline VII-6 & Male & 4 & - & not applicable & not applicable & normal \\
\hline
\end{tabular}

of 32 patrilineal relatives exhibited bilateral, symmetric, and sensorineural hearing impairment as a sole clinical phenotype. These subjects did not have a history of exposure to aminoglycosides or of other causes known to account for the hearing impairment.

The proband (V-21) began suffering hearing impairment at the age of 27 years. His hearing got worse when he had severe tinnitus at the age of 37. At the age of 45, he was evaluated by the ear, nose, and throat doctors from Chinese PLA General Hospital. Auditory evaluation, including pure tone audiometry, immittance, and auditory brainstem response, revealed that he had severe hearing impairment. As shown in fig 2A, the audiometric graph was U-shaped for the left ear but flat for the right ear. He had high tone hearing loss and continuous tinnitus. However, he had no other significant medical history.

As displayed in table 1 and figs $2 \mathrm{~A}, \mathrm{~B}$, and $\mathrm{C}$, audiometric studies showed a variable severity of hearing impairment. Of 18 patrilineal relatives who received audiometric evaluation, 11 subjects, such as V-21, exhibited severe hearing impairment (fig 2A), only subject VI-28 suffered mild hearing impairment (fig 2B), and six subjects, including V-30, showed moderate hearing impairment (fig 2C). Three young individuals, VII-2, VII-3, and VII-6, with ages of $<1,2$, and 4 years, respectively, had normal hearing. The matrilineal sons (for example, VI-14) also showed normal hearing (fig 2D). Interestingly, patrilineal relatives of this family exhibited postlingual onset or progressive, but not congenital hearing impairment. In this family, the ages of onset in the patrilineal relatives ranged from 7 to 27 years with an average of 12.7 (6.4) years. Furthermore, three of the 18 affected relatives also suffered from tinnitus. Individual VI-34 developed tinnitus at the age of 10 years, while V-19 and V-21 had tinnitus at the age of 50 and 37 years, respectively. There was no obvious vestibular dysfunction among all the patrilineal relatives.

Comprehensive examination of the family medical history of these individuals did not identify other clinical syndromes, such as cardiovascular disorders, diabetes, visual problems, or neurological diseases. Also, examinations by genome wide karyotype analysis on individuals of V-30, V-34, VI-3, VI-8, VI-10, VI-34, and V-31 (the wife of V-30) and a computed tomogram of temporal bones on the seven individuals did not show any abnormal evidence (data not shown).

Table 2 Multivariate logistic maximum likelihood estimates of segregation models for inheritance of non-syndromic hereditary hearing impairment

\begin{tabular}{|c|c|c|c|c|c|c|}
\hline & Multifactorial only & $\begin{array}{l}\text { Multifactorial+ } \\
\text { commingled }\end{array}$ & $\begin{array}{l}\text { Multifactorial+ } \\
\text { Mendelian }\end{array}$ & $\begin{array}{l}\text { Multifactorial+ } \\
\text { free } \tau^{\prime} s\end{array}$ & $\begin{array}{l}\text { Multifactorial+ } \\
\text { dominant }\end{array}$ & $\begin{array}{l}\text { Multifactorial+ } \\
\text { recessive }\end{array}$ \\
\hline$q_{\mathrm{A}}$ & (1.0) & 1.0 & 1.0 & 0.85 & 1.0 & 1.0 \\
\hline$\tau_{\mathrm{AA}}$ & $\ldots$ & $\ldots$ & (1.0) & 1.0 & (1.0) & (1.0) \\
\hline$\tau_{\mathrm{AB}}$ & $\ldots$ & $\ldots$ & $(0.5)$ & 0.0 & $(0.5)$ & $(0.5)$ \\
\hline$\tau_{\mathrm{BB}}$ & $\ldots$ & $\ldots$ & $(0.0)$ & 0.0 & $(0.0)$ & $(0.0)$ \\
\hline SUSCAA $_{A}$ & -1.64 & -1.75 & -1.62 & * & -1.65 & -1.67 \\
\hline SusC $_{A B}$ & $\ldots$ & -1.75 & -1.53 & -1.61 & -1.65 & -1.67 \\
\hline$S_{U S C_{B B}}$ & $\ldots$ & -1.75 & -1.35 & -1.61 & -1.60 & -1.67 \\
\hline$\rho_{\text {resid }}$ & 7.37 & 7.93 & 6.12 & 7.21 & 7.15 & 7.49 \\
\hline$-2 \operatorname{LnL}$ & 83.41 & 82.35 & 87.98 & 71.72 & 84.15 & 83.00 \\
\hline Akaike's AIC & 87.41 & 90.35 & 95.98 & 83.72 & 90.15 & 91.00 \\
\hline
\end{tabular}

Test $H_{01}$ : no major gene effect, $\chi^{2}=4.57, \mathrm{df}=3, \mathrm{p}=0.116$

Test $H_{02}$ : no transmission of major gene effect, $\chi^{2}=10.63, \mathrm{df}=3, \mathrm{p}=0.014$

Test $\mathrm{H}_{03}$ : Mendelian transmission, $\chi^{2}=16.26, \mathrm{df}=3, \mathrm{p}=0.001$

Test $H_{04}$ : Mendelian transmission and dominant inheritance, $\chi^{2}=3.83, \mathrm{df}=1, \mathrm{p}=0.050$

Test $H_{05}$ : Mendelian transmission and recessive inheritance, $\chi^{2}=4.98, d f=1, p=0.026$

*This parameter estimator did not converge well, but the hypotheses can still be tested by comparing the models. 


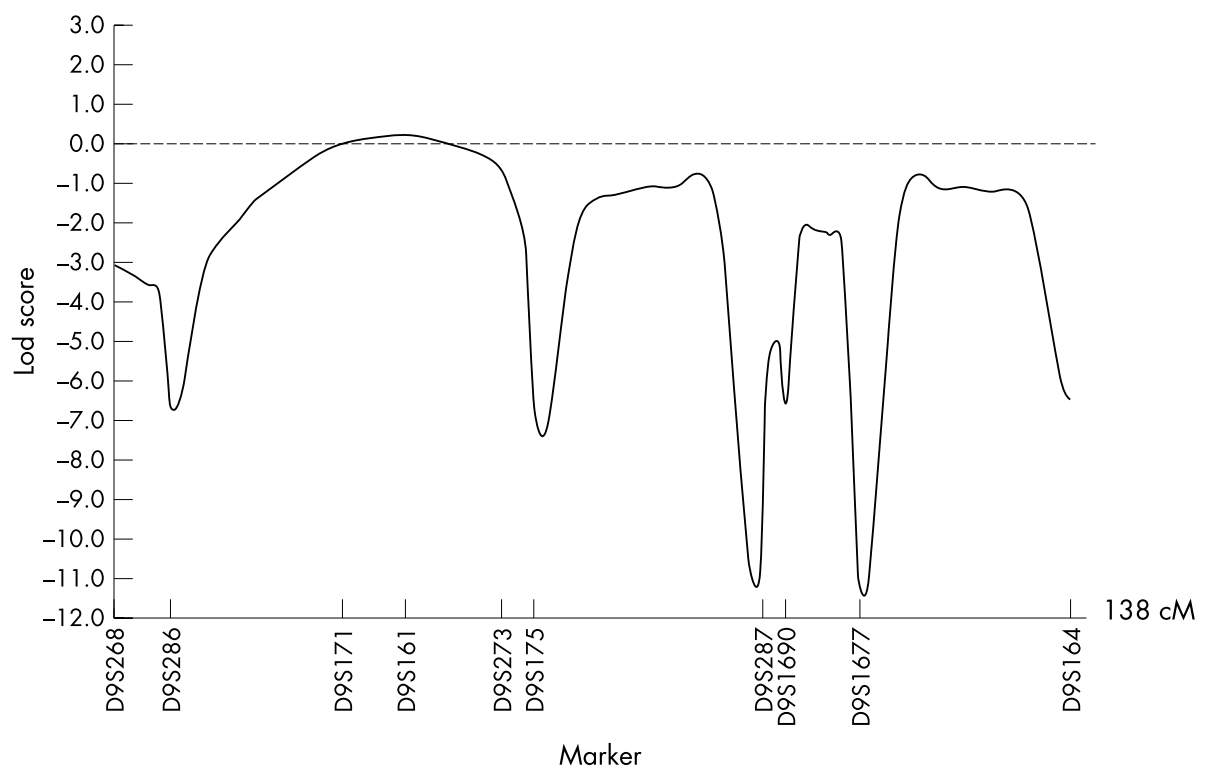

Figure 3 Multipoint lod score analysis of non-syndromic hearing impairment. Genotypes at D9S288, D9S286, D9S171, D9S161, D9S273, D9S175, D9S287, D9S1690, D9S1677, and D9S164 were used to determine the multipoint lod scores at chromosome 9q21. D9S288 is arbitrarily plotted at $0 \mathrm{cM}$ at abscissa. Other microsatellite markers embracing the $9 q 21$ are indicated along the abscissa from telomere to centromere. Multipoint lod score is plotted on the ordinate.

\section{Segregation analysis}

Complex segregation analysis was employed to investigate the inheritance pattern within the pedigree. Parameter estimates for six different models are shown in table 2. The null hypothesis of no major type effect was assessed by comparing the model containing multifactorial inheritance alone $\left(H_{01}: q_{\mathrm{A}}=1\right)$ with that containing both a Mendelian major gene and multifactorial inheritance $\left(H_{\mathrm{Al}}: 0<q_{\mathrm{A}}<1 ; \tau_{A A}=1.0, \tau_{\mathrm{AB}}=0.5, \tau_{\mathrm{BB}}=0.0\right)$. The model with both effects has three additional parameters $\left(q_{\mathrm{A}}\right.$ and two susceptibilities), so the likelihood ratio statistic $\left(\chi^{2}\right)$ has three degrees of freedom (df). The null hypothesis of no transmission of major gene effects was tested by comparing the commingled model $\left(H_{02}: q_{\mathrm{A}}=\tau_{\mathrm{AA}}=\tau_{\mathrm{AB}}=\tau_{\mathrm{BB}}\right)$ with the model in which all transmission probabilities were estimated $\left(H_{\mathrm{A} 2}: q_{\mathrm{A}} \neq \tau_{\mathrm{AA}} \neq \tau_{\mathrm{AB}} \neq \tau_{\mathrm{BB}}, 3 \mathrm{df}\right)$. The null hypothesis of Mendelian transmission was tested by comparing the mixed Mendelian model $\left(H_{03}: \tau_{\mathrm{AA}}=1.0, \tau_{\mathrm{AB}}=0.5, \tau_{\mathrm{BB}}=0.0\right)$ with a model where all transmission probabilities were estimated $\left(H_{\mathrm{A} 3}\right.$ : free $\left.\tau^{\prime} \mathrm{s}, 3 \mathrm{df}\right)$. The null hypothesis of dominant Mendelian inheritance $\left(H_{04}\right)$ was tested by comparing the model of the mixed Mendelian model (the general model) with the mixed model $\left(\right.$ Susc $_{\mathrm{AA}}=$ Susc $_{\mathrm{AB}} \neq$ Susc $\left._{\mathrm{BB}}, \quad \mathrm{l} \mathrm{df}\right)$. The null hypothesis $\left(H_{05}\right.$ :
$\operatorname{Susc}_{\mathrm{AA}} \neq$ Susc $_{\mathrm{AB}}=\operatorname{Susc}_{\mathrm{BB}}$ ) of recessive Mendelian inheritance was tested in similar way.

The hypothesis of no major effect was not rejected $\left(\chi^{2}=4.57, \mathrm{df}=3, \mathrm{p}=0.116\right)$, but the hypothesis of no transmission of the major effect was rejected $\left(\chi^{2}=10.63\right.$, $\mathrm{df}=3, \mathrm{p}=0.014)$. This discrepancy between the two tests might be due to the fact that the two models for $H_{01}$ are not hierarchical with each other and thus the test for $H_{01}$ is less powerful, although such a test was extensively used in the segregation analysis. ${ }^{14}$ As expected, the hypothesis of Mendelian transmission was strongly rejected $\left(\chi^{2}=16.26\right.$, $\mathrm{df}=3, \mathrm{p}=0.001)$. Not surprisingly, both dominant and recessive Mendelian inheritance models were rejected with $p=0.05$ and 0.026 , respectively. These results clearly support the conjecture that a putative major gene was segregating in the large and extended pedigree in some manner (like sex linked inheritance) other than autosomal Mendelian inheritance.

\section{Linkage analysis}

To gain further evidence for sex linked inheritance and to exclude the possibly autosomal inheritances in this pedigree, we carried out a genome wide scan using genomic DNA derived from 42 individuals ( 24 males, 18 females) of this

Table 3 Two point lod scores between the disease locus and the chromosome 9 markers

\begin{tabular}{|c|c|c|c|c|c|c|c|}
\hline \multirow[b]{2}{*}{ Marker } & \multicolumn{5}{|c|}{ Lod score ${ }^{*}$ at $\theta=$} & \multirow[b]{2}{*}{$Z_{\max }$} & \multirow[b]{2}{*}{$\theta_{\max }$} \\
\hline & 0.0 & 0.1 & 0.2 & 0.3 & 0.4 & & \\
\hline D9S288 & -7.65 & -2.67 & -1.14 & -0.46 & -0.12 & 0.00 & 0.51 \\
\hline D9S286 & -12.71 & -3.59 & -1.73 & -0.80 & -0.28 & 0.10 & 0.61 \\
\hline D9S171 & 0.61 & 0.63 & 0.48 & 0.26 & 0.07 & 0.65 & 0.05 \\
\hline D9S161 & -3.47 & 0.97 & 0.86 & 0.59 & 0.28 & 0.10 & 0.98 \\
\hline D9S273 & 1.37 & 1.24 & 0.98 & 0.66 & 0.33 & 1.37 & 0.00 \\
\hline D9S175 & -9.37 & -1.40 & -0.39 & -0.05 & 0.04 & 0.04 & 0.42 \\
\hline D9S287 & -12.23 & -1.23 & -0.42 & -0.10 & 0.01 & 0.02 & 0.44 \\
\hline D9S1690 & -11.96 & -1.16 & -0.31 & 0.02 & 0.10 & 0.10 & 0.39 \\
\hline D9S1677 & -21.51 & -3.25 & -1.48 & -0.59 & -0.14 & 0.00 & 0.50 \\
\hline D9S164 & -7.86 & -0.97 & -0.22 & 0.04 & 0.09 & 0.09 & 0.38 \\
\hline
\end{tabular}


Chinese family. Three hundred and eighty two microsatellite markers spanning the 22 autosomes were used. This analysis showed a weak positive two point lod score at seven markers (D3S1701, D3S1297, D4S1539, D7S519, D8S284, D8S1771, and D9S273), ranging from 0.5 to 1.31 (at recombination rate, $\theta=0.1)$. Of these, the highest lod score was obtained at D9S273 (maximum lod score, $Z_{\max }=1.37, \theta=0.0$, see table 3). To further confirm or reject the linkage at D9S273 (9q21), we carried out a multipoint linkage analysis using nine markers nearby the peak on chromosome 9, namely D9S288, D9S286, D9S171, D9S161, D9S175, D9S287, D9S1690, D9S1677, and D9S164, as well as the peak itself at D9S273, and the result is shown in fig 3. Because the striking feature in this family is extremely high penetrance $(91 \%)$ in the patrilineal relatives, but almost no penetrance in the matrilineal relatives, we might well assume that this particular hearing disorder is a sex limited trait with male restricted phenotypic expression (and a null penetrance in females). We tested this hypothesis by performing the above multipoint analysis but with the phenotypes of female siblings set as unknown. The resulting multipoint linkage profile resembles fig 3, and the corresponding linkage peak is too small to implicate a genome wide significant linkage (data not shown). In summary, the multipoint linkage analyses essentially excluded the putative linkage region, thereby supporting our proposition of the Y-linked inheritance in the large and extended pedigree.

\section{DISCUSSION}

In this study, we performed clinical and genetic characterisation of a large Chinese family with non-syndromic deafness. The clinical phenotype was only present in the paternal lineage of this seven generation pedigree. This suggests that the Y-linked inheritance is most probably the mode of transmission within this family. All affected individuals share some common features: bilateral, symmetrical, purely sensorineural but not any conductive component. Unlike families in which deafness is transmitted with autosomal dominant, recessive or $\mathrm{X}$-linked modes, ${ }^{3}$ the striking feature in this family is the extremely high penetrance $191 \%$ in patrilineal relatives), although the patrilineal relatives in this Chinese pedigree exhibited phenotypic variability including the severity and age of onset. The severity of hearing impairment in this family ranged from mild to severe, but not to profound. The ages of onset for the patrilineal relatives in this family were from 7 to 27 years.

To determine whether familial aggregation of nonsyndromic hereditary hearing loss in this pedigree could reflect the action of a single major gene and the mode of inheritance, we performed a segregation analysis with the S.A.G.E. program SEGREG. The likelihood ratio tests for hypotheses of genetic transmission indicate that a putative major gene was segregating in the pedigree $(p=0.014)$, but it does not follow autosomal Mendelian inheritance $(p=0.001)$. Further segregation analysis excluded both dominant and recessive inheritance models for the pedigree. To gain further evidence for sex linked inheritance and to exclude the possible autosomal inheritance, we carried out a genome-wide scan using 382 microsatellite markers spanning the 22 autosomes. Two point and multipoint linkage analysis showed that there is not any significant lod score large enough to implicate an autosomal inheritance locus. Cross validations by comprehensive medical investigation, complex segregation analysis, and model based linkage analysis agree with each other and strongly support the notion that Y-linked inheritance is the mode of genetic transmission within this family.

One possibility might be that a chromosomal translocation involving the Y long arm segregates in this family. However, we were able to exclude any conspicuous chromosomal rearrangement since the karyotypes analysed in seven members (six affected males and one unaffected female) were normal. Therefore, a mutation in a putative $\mathrm{Y}$ chromosome linked gene is likely to account for the inheritance pattern. A Y-specific gene without a homologue on the $\mathrm{X}$ chromosome, would be expressed in males only, hence would have to be required for normal hearing in males but not in females. In all likelihood, the disease gene may rather have a functional counterpart on the X chromosome. The gene could thus be located in the pseudo-autosomal region, close to the boundary with the male specific region of the Y containing the SRY sex determining gene (otherwise the probability would be high that the hearing impairment also affects some females in this family). Alternatively, the gene is located in the male specific region of the $\mathrm{Y} .{ }^{18}$ Of 78 protein coding genes identified in this region, we suggest that PCDH11Y, encoding a protocadherin, is an attractive candidate on the following grounds. Firstly, it has a functional homologue, PCDHIIX, on the X chromosome. ${ }^{19}{ }^{20}$ Secondly, two other members of the cadherin family, protocadherin 15 and cadherin23, have been involved in syndromic and nonsyndromic deafness forms. ${ }^{21-23}$

\section{ACKNOWLEDGEMENTS}

We thank two anonymous reviewers for their helpful comments on an early version of the manuscript. We also thank the patients and their families for their cooperation during this work, the China Association of the Handicapped for their assistance in our investigations and Dr Yuehui Liu at the Second Affiliated Hospital of Jiang Xi Medical College for his help during pedigree investigations.

\section{Authors' affiliations}

Q J Wang, D Y Han, J Y Cao, L M Yu, Q Z Li, W Y Yang, Department of Otorhinolaryngology/Head and Neck Surgery, Institute of Otolaryngology, Chinese PLA General Hospital, Beijing 100853, PR China

C Y Lu, Q J Wang, Y Shen, Chinese National Human Genome Centre, Beijing 100176, PR China

N Li, The State Key Laboratory for Agro-biotechnology, China Agricultural University, Beiiing 100094, PR China

S Q Rao, Center for Cardiovascular Genetics, Department of Cardiovascular Medicine, the Cleveland Clinic Foundation, 9500 Euclid Avenue, Cleveland, Ohio 44195, USA

M X Guan, Division and Program in Human Genetics, Cincinnati Children's Hospital Medical Center, Cincinnati, Ohio 45229, USA Y B Shi, Tinnitus Clinic, Oregon Health and Science University, Portland, Oregon 97239, USA

$\mathbf{X}$ Li, Department of Biomedical Engineering, Biomathematics, and Bioinformatics, Harbin Medical University, Harbin 150086, PR China

This work was supported by grants from the Beijing Natural Science Foundation (Grant No 701 1004), the National High Tech Development Project (Grant Nos 2001AA221092 and 2002AA222052), the National Natural Science Foundation of China (Grant Nos 30170515 and 39970397), and Beiijing Science and Technology Innovation Project (Grant No H010210160119).

Conflicts of interest: none declared.

Correspondence to: Professor W Y Yang, Institute of Otolaryngology, Chinese PLA General Hospital, 28 Fuxing Road, Beijing 100853, PR China; ywy301@263.net

\section{REFERENCES}

1 Morton NE. Genetic epidemiology of hearing impairment. Ann N Y Acad Sci 1991;630:16-31.

2 Marazita ML, Ploughman LM, Rawlings B, Remington E, Arnos KS, Nance WE. Genetic epidemiological studies of early-onset deafness in the U.S. school-age population. Am J Med Genet 1993;46:486-91.

3 Petit C, Levilliers J, Hardelin JP. Molecular genetics of hearing loss. Annu Rev Genet 2001;35:589-646.

4 Morton CC. Genetics, genomics and gene discovery in the auditory system. Hum Mol Genet 2002;11:1229-40. 
5 Lalwani AK, Castelein CM. Cracking the auditory genetic code: nonsyndromic hereditary hearing impairment. Am J Otol 1999;20:115-32.

6 Resendes BL, Williamson RE, Morton CC. At the speed of sound: gene discovery in the auditory system. Am J Hum Genet 2001;69:923-35.

7 Steel KP, Kros CJ. A genetic approach to understanding auditory function. Nat Genet 2001;27:143-9.

8 Wang Q, Gu R, Han D, Yang W. Familial auditory neuropathy. Laryngoscope 2003;113:1623-9.

9 Zhao H, Li R, Wang Q, Yan Q, Deng JH, Han D, Bai Y, Young WY, Guan MX Maternally inherited aminoglycoside-induced and nonsyndromic deafness is associated with the novel C1494T mutation in the mitochondrial 12S rRNA gene in a large Chinese family. Am J Hum Genet 2004;74:139-52.

10 Stephens $D$. Definitions, protocols \& guidelines in genetic hearing impairment In: Martini A, Mazzoli M, Stephens D, Read A, eds. Audiological terms. Letchworth, UK: Whurr Publishers, 2001.

11 S.A.G.E. (Statistical Analysis for Genetic Epidemiology), ver 4.4. A computer program package available from Statistical Solutions. Cork, Ireland: Statistical Solutions, 2003.

12 Karunaratne PM, Elston RC. A multivariate logistic model (MLM) for analyzing binary family data. Am J Med Genet 1998;76:428-37.

13 Bonney GE. Regressive logistic models for familial disease and other binary traits. Biometrics 1986;42:61 1-25.

14 Hanson RL, Elston RC, Pettitt DJ, Bennett PH, Knowler WC. Segregation analysis of non-insulin-dependent diabetes mellitus in Pima Indians: evidence for a major-gene effect. Am J Hum Genet 1995;57:160-70.

15 Elston RC. Segregation analysis. Adv Hum Genet 1981;11:63-120, 372-3.

16 Lathrop GM, Lalouel JM. Easy calculations of lod scores and genetic risks on small computers. Am J Hum Genet 1984;36:460-5.

17 Kruglyak L, Daly MJ, Reeve-Daly MP, Lander ES. Parametric and nonparametric linkage analysis: a unified multipoint approach. Am J Hum Genet 1996;58:1347-63.
18 Skaletsky H, Kuroda-Kawaguchi T, Minx PJ, Cordum HS, Hillier L, Brown LG, Repping S, Pyntikova T, Ali J, Bieri T, Chinwalla A, Delehaunty A, Delehaunty K, Du H, Fewell G, Fulton L, Fulton R, Graves T, Hou SF, Latrielle P Leonard S, Mardis E, Maupin R, McPherson J, Miner T, Nash W, Nguyen C, Ozersky P, Pepin K, Rock S, Rohlfing T, Scott K, Schultz B, Strong C, TinWollam A, Yang SP, Waterston RH, Wilson RK, Rozen S, Page DC. The malespecific region of the human $Y$ chromosome is a mosaic of discrete sequence classes. Nature 2003:423:825-37.

19 Yoshida K, Sugano S. Identification of a novel protocadherin gene (PCDH1 1) on the human XY homology region in Xq21.3. Genomics 1999;62:540-3.

20 Blanco P, Sargent CA, Boucher CA, Mitchell M, Affara NA. Conservation of $\mathrm{PCDHX}$ in mammals; expression of human $\mathrm{X} / \mathrm{Y}$ genes predominantly in brain. Mamm Genome 2000;11:906-14.

21 Alagramam KN, Yuan H, Kuehn MH, Murcia CL, Wayne S, Srisailpathy CR Lowry RB, Knaus R, Van Laer L, Bernier FP, Schwartz S, Lee C, Morton CC, Mullins RF, Ramesh A, Van Camp G, Hageman GS, Woychik RP, Smith RJ, Hagemen GS. Mutations in the novel protocadherin PCDH15 cause Usher syndrome type 1F. Hum Mol Genet 2001;10:1709-18.

22 Bork JM, Peters LM, Riazuddin S, Bernstein SL, Ahmed ZM, Ness SL, Polomeno R, Ramesh A, Schloss M, Srisailpathy CR, Wayne S, Bellman S Desmukh D, Ahmed Z, Khan SN, Kaloustian VM, Li XC, Lalwani A, BitnerGlindzicz M, Nance WE, Liu XZ, Wistow G, Smith RJ, Griffith AJ, Wilcox ER, Friedman TB, Morell RJ. Usher syndrome ID and nonsyndromic autosomal recessive deafness DFNB12 are caused by allelic mutations of the novel cadherin-like gene CDH23. Am J Hum Genet 2001;68:26-37.

23 Ahmed ZM, Riazuddin S, Ahmad J, Bernstein SL, Guo Y, Sabar MF, Sieving P, Griffith AJ, Friedman TB, Belyantseva IA, Wilcox ER. PCDH15 is expressed in the neurosensory epithelium of the eye and ear and mutant alleles are responsible for both USHIF and DFNB23. Hum Mol Genet $2003 ; 12: 3215-23$. 